\title{
Rational Route of Delivery Mesenchymal Stem Cell Therapy for Acute Myocardial Infarction (AMI) and Chronic Ischemic Cardiomyopathy (ICM): a Systematic Review and Meta-analysis
}

Huang Yan ting

Shantou University Medical College https://orcid.org/0000-0002-9917-9439

Lin Weizhao

Second Affiliated Hospital of Shantou University Medical College

Yang Xiangbin

Shantou University Medical College

Chen Shuqing

Shantou University Medical College

Gao Kai

Shantou University Medical College

Su Yiwan

Shantou University Medical College

\section{Lin Zhishan}

Shantou University Medical College

\section{Xu Meiling}

Shantou University Medical College

\section{Li Zhi ( $D$ lizhi519@126.com )}

Second Affiliated Hospital of Shantou University Medical College

\section{Research Article}

Keywords: Mesenchymal stromal cell, stem cell therapy, Acute myocardial infarction, chronic ischemic cardiomyopathy, route of delivery, meta-analysis

Posted Date: June 1st, 2021

DOl: https://doi.org/10.21203/rs.3.rs-564725/v1

License: (a) This work is licensed under a Creative Commons Attribution 4.0 International License. Read Full License 


\section{Abstract}

Background: Recent studies suggest that mesenchymal stem cells (MSCs) may have therapeutic potential for both acute myocardial infarction (AMI) and chronic ischemic cardiomyopathy (ICM). However, the rational route of delivery MSC therapy has not reached consensus. We performed a systematic review of clinical trials evaluating the rational route of delivery MSCs for AMI or ICM.

Methods: Databases including Embase, PubMed, and Cochrane Central Register of Controlled Trials were searched from inception to February 2021. Studies that examined the use of MSCs in adults with AMI or ICM were eligible. Bias of included studies were assessed by the Cochrane risk of bias tool. The primary outcome was cardiac function assessed by left ventricular ejection fraction (LVEF) and the secondary outcome was cardiac remodeling which was assessed by left ventricular end-systolic volume (LVESV) and left ventricular end-diastolic volume (LVEDV), we also explored the safety between different routes.

Results: 18 studies fulfilled eligibility criteria, which consist of 11 studies evaluated AMI and 7 studies evaluated ICM. In AMI group, only when patients received intracoronary infusion(IC) can improve LVEF (SMD 0.88, 95\% $\mathrm{Cl}$ 0.64-1.12), and there was a decrease in LVEDV\&LVESV when administered IC or intravenous infusion (IV). While in ICM group, no significant difference in LVEF was noted no matter administered which route, and transendocardial stem cell injection(TESI) seems to be effective in decreasing LVEDV\&LVESV. Safety appeared no difference between different routes.

Conclusions: Results from our systematic review suggest that intracoronary infusion seems more effective for MSC's delivery in AMI group, while in ICM group, TESI better.

\section{Background}

Cardiovascular disease caused by ischemic injury represent a major cause of mortality worldwide ${ }^{[1]}$. Currently, no therapeutic solutions are available for long-term management except for heart transplant, indicating the demand for new approaches to prevent and reverse cardiac dysfunction ${ }^{[2]}$.Display remarkable promise for myocardial regeneration, cell-based therapy has gained a lot of attention in the last few decades ${ }^{[3]}$. Recent studies has suggested that mesenchymal stem cells (MSCs) may be more effective than other cell types ${ }^{[4,5]}$, and MSCs therapy ischemic heart disease appears to be safe and effective ${ }^{[6,7]}$.The basic mechanisms are suggested to include:(1) differentiate and incorporate into the host tissue ${ }^{[8]}$; (2) paracrine effect, which can ameliorate oxidative stress and inflammation ${ }^{[9-11]}$,induce neovascularization ${ }^{[12]}$, anti-apoptosis ${ }^{[13]}$, reduce collagen deposition ${ }^{[14]}$. However, there is still debate regarding the best patient group, source of cells, timing of administration, and the optimal route. Compared to other factors, the rational route was less discussed. Up to today, the route of delivery MSCs included intracoronary infusion (IC), directly intramyocardial injection (DI), transendocardial/transepicardial stem cell injection(TESI) and intravenous infusion (IV). The route of delivery makes a major influence on grafting efficiency and survival of transplanted cells in the infarcted 
region of the heart, which means that finding an optimal route can lead to better clinical outcomes for cell therapy. Thus, we try to explore the optimal route of Mesenchymal Stem Cell(MSC) delivery.

\section{Methods}

\section{Search strategy}

We searched for trials in databases including PubMed, EMBASE, and the Cochrane Central Register of Controlled Trials (CENTRAL) registry of the Cochrane Collaboration until February 2021. The following search terms were used alone or in combination: mesenchymal stromal cells, mesenchymal stem cells, MSCs, mesenchymal stem cell transplantation, multipotent mesenchymal stromal cells, bone marrow mesenchymal stem cells, adipose-derived mesenchymal stem cells, Wharton's Jelly Cells, Myocardial Infarction, Myocardial Ischemia, Cardiovascular Stroke, Heart Attack, Ischemic Heart Disease. Two review authors identified all studies independently. The search was limited to controlled studies with a comparator arm. No language limit was applied. Any disagreement relating to the eligibility of a particular study was settled through discussion with senior reviewers.

\section{Eligibility criteria}

Inclusion criteria for this analysis were as follows: (1) Only unmodified MSCs were included, any pretreated, genetically engineered, or transfected cell were excluded; (2)The resources(bone marrow, umbilical cords, or adipose tissue) and administration route were unrestricted; (3) studies that were conducted in patients who had Ischemic cardiomyopathy; (4) Both cell groups and control arms should receive standard therapy, the control arm did not receive stem cells.

\section{Data extraction and quality assessment}

A standardized data extraction form was used to extract data from the included studies. Information extracted included: study setting (publication year and country); demographics and baseline characteristics of the study population; details of the intervention and control conditions, such as cell delivery route, resource, dose, time interval between PCI to injection, change in LVEF, LVESV, LVEDV, follow-up duration; information for assessment of the risk of bias. Data was extracted independently by two review authors, discrepancies identified were settled by discussion with senior reviewers.

\section{Summary measures}

Change in LVEF is our primary outcome measures, many methods were used measuring LVEF(\% EF), echocardiography data were used in preference unless MRI data were available. Change in LVEDV and LVESV were used as secondary outcome measures. In addition, we explore safety within different routes.

\section{Method for meta-analysis}


The data were analysed using Stata 16.0 (Stata Corporation, College Station, TX). The mean difference (MD) was used for continuous variables, while Forest plots were used to present the results of our metaanalysis. When studies that contained more than two treatment arms, only control and MSC groups were analyzed Values pooled together using mean, standard deviation, and size for studies conducting more than one experimental group containing MSCs. $\mathrm{P}<0.05$ was considered statistically significant and twosided $95 \% \mathrm{Cl}$ were reported throughout the study. Chi-square-based Q test and $\mathrm{I} 2$ tests were used to assess the quantity of heterogeneity among these studies. When $12<50 \%, p>0.1$, the pieces of evidences were thought to be acceptable heterogeneity, the fixed-effects model would be used. Otherwise, the randomeffects model was applied.

\section{Results}

\section{Search results}

Ultimately, 18 clinical trials which investigating the effect of MSC therapy on AMI and ICM were included in the meta-analysis $(n=1055)^{[15-32]}$. Characteristics of the enrolled clinical studies are shown in Table 1.

In included trials, intracoronary infusion $(I C)(n=9)$ was the most common route of delivery stem cells, followed by transendocardial stem cell injection(TESI) $(n=6)$, intravenous infusion $(I V)(n=2)$ and directly intramyocardial injection (DI) $(n=1)$. Most of studies $(n=13)$ applied autologous/ allogeneic adult human bone marrow-derived mesenchymal cells $[16,17,19-25,27-29,32]$. 3 study investigated the use of autologous adipose tissue-derived mesenchymal cells ${ }^{[15,30,31]}$.The remaining studies utilised varied allogeneic cell sources such as mesenchymal cells from umbilical cord blood $(n=2)^{[18,26]}$. We performed a further metaanalysis on 11 AMl clinical trials $(n=550 \text { patients })^{[15-25]}$, characteristics of which are presented in Table 2, and performed on 7 ICM clinical trials $(n=505)^{[26-32]}$, characteristics of which are depicted in Table 3.(More detailed information outlined in Supporting Information Appendix 1\&2)

\section{Primary outcomes--cardiac function}

\section{Left Ventricular Ejection Fraction (LVEF)}

Compared to control, Patients receiving MSCs had a significantly increased in LVEF (SMD $0.37,95 \% \mathrm{Cl}$ $0.23-0.50,12=94.3 \%)$. MSC administered through intracoronary (IC), transendocardial stem cell injection(TESI), intravenous(IV) and directly intramyocardia(DI) have shown the potential to increase LVEF, when referring to the optional administration route, MSCs increased LVEF only when applied intracoronary injection (SMD 0.69,95\% CI 0.47-0.91, I 2 = 96.6\%)(Fig. 1), while when we performed a further meta-analysis within AMI and ICD patients, statistically significant difference was found in LVEF when administered different route

LVEF subgroup analysis 
In AMI clinical trials, MSCs increased LVEF only when intracoronary injection was applied(SMD 0.88,95\% CI 0.64-1.12, I 2 = 96.8\%), and no difference in LVEF whether administered TESI (SMD 0.40,95\% CI -0.371.17 ) or intravenously (SMD $0.01,95 \% \mathrm{Cl}-0.44-0.47$ ). While in ICD clinical trials, it seems no difference in the increase in LVEF no matter applied which route. (SMD $0.10,95 \% \mathrm{Cl} 0.09-0.29, \mathrm{I} 2=84.3 \%$ ).

Using a sensitivity analysis, significant heterogeneity was found in the trials reported by Wang ${ }^{[22]}$ and Gao et al ${ }^{[18]} . \mathrm{I}^{2}$ decreased from $95.7 \%$ to $68.7 \%$ when the data from Wang ${ }^{[22]}$ and Gao et al. ${ }^{[18]}$ were excluded.

\section{Secondary outcomes--cardiac remodeling}

\section{LVEDV \& LVESV}

A total of 7 AMI studies and 4 ICD studies provided data on LVEDV. Patients who underwent intravenous or intracoronary decreased LVEDV significantly in AMI clinical trials. While in ICD clinical trials, the route included in was only TESI way, which limited our assessment of other pathways ,and TESI displayed an effective role on reducing cardiac remodeling (SMD -0.23,95\% $\mathrm{Cl}-0.43-0.03$ ). The above results were also appeared in LVESV.

\section{Tertiary Outcomes--safety}

\section{Mortality}

9 AMI studies and 5 ICM studies reported mortality. Patients no matter AMI or ICM showed no difference in mortality(RR $0.90,95 \% \mathrm{Cl} 0.56-1.43)$, the same result was observed no matter administered which route.

\section{Sever adverse event}

3 AMI studies and 4 ICM studies reported Sever adverse event. No significant difference in the risk of mortality between MSC and control groups, no matter in which group or administered which route. Interestingly, there was seems a trend to reduce sever adverse event when TESI was applied in ICM group, though it was not statistically significant.

\section{Rehospitalization}

$6 \mathrm{AMI}$ studies and 3 ICM studies provided data on readmission. In these trials, AMI group included IC and IV way, while only TESI is incorporate in ICM group, which makes it difficult to analysis the optimal route for reducing readmission between AMI or ICM group. Under such limited condition, we found that TESI showed a subtle advantage on reducing rehospitalization(SMD 0.6,95\%Cl 0.37-0.96).

\section{Other outcomes}

\section{WMSI}


In AMI group, WMSI was more significantly decreased when use IC than TESI injection, and there were no significant differences between MSC-and placebo-treated patients when applied IV injection(data not shown).WMSI was rarely reported in ICD group, thus we can't know its real efficacy.

\section{6min-walk}

A total of 4 studies reported 6 min-walk in ICD group, there were no significant differences between MSCand placebo-treated patients when use DI or TESI way. 6 min-walk was rarely reported in AMI group and it limit our conclusion.

No comparisons are made between other outcomes like infarct size, myocardial perfusion, NYHA class, quality of life due to its insufficient reports in studies included.

\section{Risk of Bias Assessment}

Two studies met all seven criteria for low risk of bias. Two studies fulfilled six of seven risk of bias criteria. Seven studies described a low risk of bias in randomization procedures. Four studies underwent allocation concealment with low risk of bias. For Double-blinding procedures, six studies met low risk of bias. One study had a high risk of bias due to incomplete outcome data reporting and three study had an unclear risk of bias for selective reporting. None of the studies were considered to be at high risk for other biases.

\section{Discussion}

During the past decades, mesenchymal stem cell(MSC) have been extensively used in various forms of restorative and preventive medicine, which have shown conflicting and inconclusive effects in ischemic cardiomyopathy, reasons for this owing to vast differences within various clinical trials, like patient profiles, cell phenotypes, dosing, routes of delivery, study endpoints and design, making it challenge to figure out an optimal intervention. Our systematic review try to assess the optimal route of MSC therapy for AMI and ICM. We major focused our review on cardiac performance and cardiac remodeling, and we found that In AMI group, only when patients received intracoronary infusion(IC) can improve LVEF (SMD $0.88,95 \% \mathrm{Cl}$ 0.64-1.12), and there was a decrease in LVEDV\&LVESV when administered IC or intravenous infusion (IV). While in ICM group, no significant difference in LVEF was noted no matter administered which route, and transendocardial stem cell injection(TESI) seems to be effective in decreasing LVEDV\&LVESV. Safety appeared no difference between different routes. Results from our systematic review suggest that intracoronary infusion seems more effective for MSC's delivery in AMI group, while in ICM group, TESI better.

There is a large heterogeneity in our study, $\mathrm{I}^{2}$ decreased from $95.7 \%$ to $68.7 \%$ when the data from Wang ${ }^{[22]}$ and Gao et al. ${ }^{[18]}$ were excluded. When we tried to figure out the source of heterogeneity in these studies, we found that these trials were different from other studies in the transplantation timing and dosage. The cell dosage used in most studies ranged from $10^{6} \sim 10^{7}$, which was the rational cell dosage 
suggested from Zi Wang ${ }^{[33]}$ 's meta-analysis, while Wang et al. ${ }^{[22]}$ used $2 \times 10^{8}$ cells, this may be one of the reasons why this study had little effect on the improvement of LVEF. The time interval from $\mathrm{PCl}$ to injection in most studies is 15 30 days, Gao et al. ${ }^{[18]}$ only used 5 days, the best transplantation timing reported by Zi Wang ${ }^{[33]}$, this may can explain why the improvement in cardiac function from this studies was more noticeable.

The finding above is different from kanelidis ${ }^{[34]}$ et al. study, one potential explanation for these results is that only 6 clinical trials were included, which makes it difficult to make firm conclusions. In addition to including more studies, we took chronic ischemic myopathy patients into account, and it turn out to be a completely different result on cardiac function and cardiac remodeling when compared with AMI clinical trials, which seems to indicate distinct mechanisms between both AMI and ICD when administered different route of MSC delivery.

Intramyocardial injection(IM) consists of DI and TESI. DI requires directly injecting stem cells into and around the infarcted area of the heart under thoracotomy, which would increase risks for complications, morbidity and mortality. TESI means injecting stem cells into the myocardium directly through the endocardium, which is a minimally invasive surgery. All studies included use the NOGA system (Biosense Webster) for imaging. IV refers to the cells infused from peripheral vein, cells will migrate toward the injured myocardium depending on preponderance of physiological homing signals. IC means delivering MSCs through the coronary vessel to the infarcted myocardial regions. The route of delivery makes a major influence on grafting efficiency and survival of transplanted cells in the infarcted region of the heart.

For patients with acute myocardial infarction, Forest VF et al. ${ }^{[35]}$ reported a significant cell fraction retained within the heart after intracoronary injection, whereas no cardiac homing was observed in IV group. In addition, study from Hayashi $\mathrm{M}^{[36]}$ showed that the survival of BMCs in the infarcted area was significantly higher in the IM group than in the IV groups. Therefore, IV route means the least cell implantation and retention. In theory, retention of BMCs in the IM group should be higher than IC group ${ }^{[37]}$, however, Fukushima $S$ et al. ${ }^{[38]}$ found that the IM and IC groups showed a similar survival of donor cell, which may due to the harsh microenvironment in infarcted heart. The hypoxic-ischemic and inflammatory microenvironments in the ischemic myocardium lowers survival and viability of $\mathrm{MSCs}^{[39]}$,besides, exosomes from injured cardiomyocytes accelerates transplanted bone marrow mesenchymal stem cells injury ${ }^{[40]}$. Distinct cell clusters were found from immunohistochemistry when stem cell injection through intramyocardial, containing donor-derived cells and accumulated host-derived inflammatory cells in the infarct border zone ${ }^{[41,42]}$ showed that the cells were engulfed in macrophages that had infiltrated the injection areas. In contrary, IC cell injection provided more homogeneous donor cell dissemination with less inflammation and without disrupting the native myocardial structure.

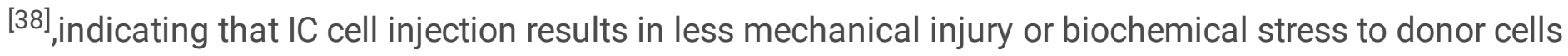
than IM cell injection does. 
For patients with chronic ischemic myopathy, mesenchymal stem cell therapy has no significant effect on increasing cardiac function probably due to different pathophysiological mechanism from this vulnerable population. MSCs are thought to work primarily because of their anti-inflammatory effects, so it is perhaps not surprising that MSCs had little impact in chronic disease such as ICM, where the level of inflammatory burden is much lower. In the aspect of cardial remodeling, exosomes derived from Mesenchymal Stem Cells can promote Fibroblast-to-Myofibroblast differentiation in Inflammatory Environments and benefit cardioprotective effects ${ }^{[14]}$.Interestingly, our studies found that TESI used in ICM group show a tendency in reducing mortality when compared to DI, which may due to its minimally invasive.

\section{Limitations}

Of note, the studies we included mainly focused on small randomized controlled studies, there are few study compared all the route directly, limiting our conclusions. Therefore, further experimental and clinical studies, which contain large-scale, rigorously conducted, randomized, adequately powered, placebocontrolled, blinded designs with outcome measures based on clinically relevant markers, are required to explore direct comparison of transmission pathways.

Apart from that, outcomes were not available in all studies included, like adverse reactions, readmission rates, which led us can not compare the safety of the different routes more comprehensively. We hope that studies in the future can provide more data on safety and provide longer follow-up data so that we can understand MSC therapy's safety over time.

\section{Conclusions}

Our study reveal that in AMI clinical trials, IC appears to be the most rational route of delivery due to its reduction in cardiac remodeling and improvement of LVEF, while in ICD clinical trials, none of any route can affect cardial function, but TESI can reduce cardial remodeling.

\section{List Of Abbreviations}

AMI Acute myocardial infarction

ICD Chronic ischemic cardiomyopathy

MSC Mesenchymal stromal cell

LVEF Left ventricular ejection fraction

LVEDV Left ventricular end-diastolic volume

LVESV Left ventricular end-systolic volume 
IC Intracoronary

TESI Transendocardial stem cell injection

IV Intravenous

DI Directly intramyocardia

IM Intramyocardial injection

PCI Percutaneous coronary intervention

MRI Magnetic resonance imaging

$\mathrm{Cl}$ Confidence interval

\section{Declarations}

\section{Ethics approval and consent to participate}

Not applicable

\section{Consent for publication}

Not applicable

\section{Availability of data and materials}

Available data in this study exist in the above clinical trials.

\section{Competing interests}

The authors declare that they have no competing interests.

\section{Funding}

This work was supported by Guangdong Basic and Applied Basic Research Foundation (2018A030307056) of China; Shantou Science and Technology Plan Project Foundation (180716084010717: [2018]155; [2019]106-1) of China.

\section{Authors' contributions}

HYT and LZ contributed to the conception and design of the study. YXB and CSQ were responsible for the collection of data. HYT and LWZ performed the statistical analysis and manuscript preparation. GK,LZS,XML and SYW were responsible for checking the data. All authors were responsible for the drafting of the manuscript and read and approved the final version. 
Acknowledgements

Not applicable

\section{References}

1. Virani SS, Alonso A, Benjamin EJ, Bittencourt MS, Callaway CW, Carson AP, Chamberlain AM, Chang AR, Cheng S, Delling FN et al: Heart Disease and Stroke Statistics-2020 Update: A Report From the American Heart Association. Circulation 2020, 141(9):e139-e596.

2. Hertz MI, Aurora P, Christie JD, Dobbels F, Edwards LB, Kirk R, Kucheryavaya AY, Rahmel AO, Rowe AW, Stehlik J: Scientific Registry of the International Society for Heart and Lung Transplantation: introduction to the 2010 annual reports. J Heart Lung Transplant 2010, 29(10):1083-1088.

3. Braunwald E: Cell-Based Therapy in Cardiac Regeneration: An Overview. Circulation research 2018, 123(2):132-137.

4. Liu B, Duan C-Y, Luo C-F, Ou C-W, Sun K, Wu Z-Y, Huang H, Cheng C-F, Li Y-P, Chen M-S: Effectiveness and safety of selected bone marrow stem cells on left ventricular function in patients with acute myocardial infarction: a meta-analysis of randomized controlled trials. International journal of cardiology 2014, 177(3):764-770.

5. Psaltis PJ, Zannettino ACW, Worthley SG, Gronthos S: Concise review: mesenchymal stromal cells: potential for cardiovascular repair. Stem cells (Dayton, Ohio) 2008, 26(9):2201-2210.

6. Lalu MM, Mazzarello S, Zlepnig J, Dong YYR, Montroy J, McIntyre L, Devereaux PJ, Stewart DJ, David Mazer C, Barron CC et al: Safety and Efficacy of Adult Stem Cell Therapy for Acute Myocardial Infarction and Ischemic Heart Failure (SafeCell Heart): A Systematic Review and Meta-Analysis. Stem cells translational medicine 2018, 7(12):857-866.

7. Lemcke H, Gaebel R, Skorska A, Voronina N, Lux CA, Petters J, Sasse S, Zarniko N, Steinhoff G, David $\mathrm{R}$ : Mechanisms of stem cell based cardiac repair-gap junctional signaling promotes the cardiac lineage specification of mesenchymal stem cells. Scientific reports 2017, 7(1):9755.

8. Toma C, Pittenger MF, Cahill KS, Byrne BJ, Kessler PD: Human mesenchymal stem cells differentiate to a cardiomyocyte phenotype in the adult murine heart. Circulation 2002, 105(1):93-98.

9. Dabrowska S, Andrzejewska A, Janowski M, Lukomska B: Immunomodulatory and Regenerative Effects of Mesenchymal Stem Cells and Extracellular Vesicles: Therapeutic Outlook for Inflammatory and Degenerative Diseases. Front Immunol 2020, 11:591065.

10. Xu R, Zhang F, Chai R, Zhou W, Hu M, Liu B, Chen X, Liu M, Xu Q, Liu N et al: Exosomes derived from pro-inflammatory bone marrow-derived mesenchymal stem cells reduce inflammation and myocardial injury via mediating macrophage polarization. Journal of cellular and molecular medicine 2019, 23(11):7617-7631.

11. Zhang Z, Tian H, Yang C, Liu J, Zhang H, Wang J, Hu S, Sun Z, He K, Chen G: Mesenchymal Stem Cells Promote the Resolution of Cardiac Inflammation After Ischemia Reperfusion Via Enhancing Efferocytosis of Neutrophils. Journal of the American Heart Association 2020, 9(5):e014397. 
12. Shi W, Xin Q, Yuan R, Yuan Y, Cong W, Chen K: Neovascularization: The Main Mechanism of MSCs in Ischemic Heart Disease Therapy. Frontiers in cardiovascular medicine 2021, 8:633300.

13. Mahrouf-Yorgov M, Augeul L, Da Silva CC, Jourdan M, Rigolet M, Manin S, Ferrera R, Ovize M, Henry A, Guguin A et al: Mesenchymal stem cells sense mitochondria released from damaged cells as danger signals to activate their rescue properties. Cell Death Differ 2017, 24(7):1224-1238.

14. Shi Y, Yang Y, Guo Q, Gao Q, Ding Y, Wang H, Xu W, Yu B, Wang M, Zhao Y et al: Exosomes Derived from Human Umbilical Cord Mesenchymal Stem Cells Promote Fibroblast-to-Myofibroblast Differentiation in Inflammatory Environments and Benefit Cardioprotective Effects. Stem cells and development 2019, 28(12):799-811.

15. Houtgraaf JH, den Dekker WK, van Dalen BM, Springeling T, de Jong R, van Geuns RJ, Geleijnse ML, Fernandez-Aviles F, Zijlsta F, Serruys PW et al: First experience in humans using adipose tissuederived regenerative cells in the treatment of patients with ST-segment elevation myocardial infarction. Journal of the American College of Cardiology 2012, 59(5):539-540.

16. Zhang R, Yu J, Zhang N, Li W, Wang J, Cai G, Chen Y, Yang Y, Liu Z: Bone marrow mesenchymal stem cells transfer in patients with ST-segment elevation myocardial infarction: single-blind, multicenter, randomized controlled trial. Stem cell research \& therapy 2021, 12(1):33.

17. Kim SH, Cho JH, Lee YH, Lee JH, Kim SS, Kim MY, Lee MG, Kang WY, Lee KS, Ahn YK et al: Improvement in Left Ventricular Function with Intracoronary Mesenchymal Stem Cell Therapy in a Patient with Anterior Wall ST-Segment Elevation Myocardial Infarction. Cardiovascular drugs and therapy 2018, 32(4):329-338.

18. Gao LR, Chen Y, Zhang NK, Yang XL, Liu HL, Wang ZG, Yan XY, Wang Y, Zhu ZM, Li TC et al: Intracoronary infusion of Wharton's jelly-derived mesenchymal stem cells in acute myocardial infarction: double-blind, randomized controlled trial. BMC medicine 2015, 13:162.

19. Gao LR, Pei XT, Ding QA, Chen Y, Zhang NK, Chen HY, Wang ZG, Wang YF, Zhu ZM, Li TC et al: A critical challenge: dosage-related efficacy and acute complication intracoronary injection of autologous bone marrow mesenchymal stem cells in acute myocardial infarction. International journal of cardiology 2013, 168(4):3191-3199.

20. Chullikana A, Majumdar AS, Gottipamula S, Krishnamurthy S, Kumar AS, Prakash VS, Gupta PK: Randomized, double-blind, phase $\mathrm{I} / \mathrm{Il}$ study of intravenous allogeneic mesenchymal stromal cells in acute myocardial infarction. Cytotherapy 2015, 17(3):250-261.

21. Lee J-W, Lee S-H, Youn Y-J, Ahn M-S, Kim J-Y, Yoo B-S, Yoon J, Kwon W, Hong I-S, Lee K et al: A randomized, open-label, multicenter trial for the safety and efficacy of adult mesenchymal stem cells after acute myocardial infarction. Journal of Korean medical science 2014, 29(1):23-31.

22. Wang $X, X i$ W-C, Wang F: The beneficial effects of intracoronary autologous bone marrow stem cell transfer as an adjunct to percutaneous coronary intervention in patients with acute myocardial infarction. Biotechnology letters 2014, 36(11):2163-2168.

23. Rodrigo SF, van Ramshorst J, Hoogslag GE, Boden H, Velders MA, Cannegieter SC, Roelofs H, Al Younis I, Dibbets-Schneider P, Fibbe WE et al: Intramyocardial injection of autologous bone marrow- 
derived ex vivo expanded mesenchymal stem cells in acute myocardial infarction patients is feasible and safe up to 5 years of follow-up. Journal of cardiovascular translational research 2013, 6(5):816825.

24. Hare JM, Traverse JH, Henry TD, Dib N, Strumpf RK, Schulman SP, Gerstenblith G, DeMaria AN, Denktas AE, Gammon RS et al: A randomized, double-blind, placebo-controlled, dose-escalation study of intravenous adult human mesenchymal stem cells (prochymal) after acute myocardial infarction. Journal of the American College of Cardiology 2009, 54(24):2277-2286.

25. Chen S-I, Fang W-w, Ye F, Liu Y-H, Qian J, Shan S-j, Zhang J-j, Chunhua RZ, Liao L-m, Lin S et al: Effect on left ventricular function of intracoronary transplantation of autologous bone marrow mesenchymal stem cell in patients with acute myocardial infarction. The American journal of cardiology 2004, 94(1):92-95.

26. Ulus AT, Mungan C, Kurtoglu M, Celikkan FT, Akyol M, Sucu M, Toru M, Gul SS, Cinar O, Can A: Intramyocardial Transplantation of Umbilical Cord Mesenchymal Stromal Cells in Chronic Ischemic Cardiomyopathy: A Controlled, Randomized Clinical Trial (HUC-HEART Trial). International journal of stem cells 2020, 13(3):364-376.

27. Heldman AW, DiFede DL, Fishman JE, Zambrano JP, Trachtenberg BH, Karantalis V, Mushtaq M, Williams AR, Suncion VY, McNiece IK et al: Transendocardial mesenchymal stem cells and mononuclear bone marrow cells for ischemic cardiomyopathy: the TAC-HFT randomized trial. JAMA 2014, 311(1):62-73.

28. Mathiasen AB, Qayyum AA, Jørgensen E, Helqvist S, Fischer-Nielsen A, Kofoed KF, Haack-Sørensen $M$, Ekblond $A$, Kastrup J: Bone marrow-derived mesenchymal stromal cell treatment in patients with severe ischaemic heart failure: a randomized placebo-controlled trial (MSC-HF trial). European heart journal 2015, 36(27):1744-1753.

29. Teerlink JR, Metra M, Filippatos GS, Davison BA, Bartunek J, Terzic A, Gersh BJ, Povsic TJ, Henry TD, Alexandre $B$ et al: Benefit of cardiopoietic mesenchymal stem cell therapy on left ventricular remodelling: results from the Congestive Heart Failure Cardiopoietic Regenerative Therapy (CHART-1) study. European journal of heart failure 2017, 19(11):1520-1529.

30. Perin EC, Sanz-Ruiz R, Sánchez PL, Lasso J, Pérez-Cano R, Alonso-Farto JC, Pérez-David E, Fernández-Santos ME, Serruys PW, Duckers HJ et al: Adipose-derived regenerative cells in patients with ischemic cardiomyopathy: The PRECISE Trial. American heart journal 2014, 168(1).

31. Henry TD, Pepine CJ, Lambert CR, Traverse JH, Schatz R, Costa M, Povsic TJ, David Anderson R, Willerson JT, Kesten $S$ et al: The Athena trials: Autologous adipose-derived regenerative cells for refractory chronic myocardial ischemia with left ventricular dysfunction. Catheterization and cardiovascular interventions : official journal of the Society for Cardiac Angiography \& Interventions 2017, 89(2):169-177.

32. Chen S, Liu Z, Tian N, Zhang J, Yei F, Duan B, Zhu Z, Lin S, Kwan TW: Intracoronary transplantation of autologous bone marrow mesenchymal stem cells for ischemic cardiomyopathy due to isolated 
chronic occluded left anterior descending artery. The Journal of invasive cardiology 2006, 18(11):552-556.

33. Wang Z, Wang L, Su X, Pu J, Jiang M, He B: Rational transplant timing and dose of mesenchymal stromal cells in patients with acute myocardial infarction: a meta-analysis of randomized controlled trials. Stem cell research \& therapy 2017, 8(1):21.

34. Kanelidis AJ, Premer C, Lopez J, Balkan W, Hare JM: Route of Delivery Modulates the Efficacy of Mesenchymal Stem Cell Therapy for Myocardial Infarction: A Meta-Analysis of Preclinical Studies and Clinical Trials. Circulation research 2017, 120(7):1139-1150.

35. Forest VF, Tirouvanziam AM, Perigaud C, Fernandes S, Fusellier MS, Desfontis J-C, Toquet CS, Heymann M-FM, Crochet DP, Lemarchand PF: Cell distribution after intracoronary bone marrow stem cell delivery in damaged and undamaged myocardium: implications for clinical trials. Stem cell research \& therapy 2010, 1(1):4.

36. Hayashi M, Li T-S, Ito H, Mikamo A, Hamano K: Comparison of intramyocardial and intravenous routes of delivering bone marrow cells for the treatment of ischemic heart disease: an experimental study. Cell transplantation 2004, 13(6):639-647.

37. Hou D, Youssef EA-S, Brinton TJ, Zhang P, Rogers P, Price ET, Yeung AC, Johnstone BH, Yock PG, March KL: Radiolabeled cell distribution after intramyocardial, intracoronary, and interstitial retrograde coronary venous delivery: implications for current clinical trials. Circulation 2005, 112(9 Suppl):I150-I156.

38. Fukushima S, Varela-Carver A, Coppen SR, Yamahara K, Felkin LE, Lee J, Barton PJR, Terracciano $\mathrm{CMN}$, Yacoub MH, Suzuki K: Direct intramyocardial but not intracoronary injection of bone marrow cells induces ventricular arrhythmias in a rat chronic ischemic heart failure model. Circulation 2007, 115(17):2254-2261.

39. Li Q, Wang Y, Deng Z: Pre-conditioned mesenchymal stem cells: a better way for cell-based therapy. Stem cell research \& therapy 2013, 4(3):63.

40. Hu M, Guo G, Huang Q, Cheng C, Xu R, Li A, Liu N, Liu S: The harsh microenvironment in infarcted heart accelerates transplanted bone marrow mesenchymal stem cells injury: the role of injured cardiomyocytes-derived exosomes. Cell death \& disease 2018, 9(3):357.

41. Amsalem Y, Mardor Y, Feinberg MS, Landa N, Miller L, Daniels D, Ocherashvilli A, Holbova R, Yosef O, Barbash IM et al: Iron-oxide labeling and outcome of transplanted mesenchymal stem cells in the infarcted myocardium. Circulation 2007, 116(11 Suppl):I38-I45.

42. Terrovitis J, Stuber M, Youssef A, Preece S, Leppo M, Kizana E, Schär M, Gerstenblith G, Weiss RG, Marbán E et al: Magnetic resonance imaging overestimates ferumoxide-labeled stem cell survival after transplantation in the heart. Circulation 2008, 117(12):1555-1562.

\section{Tables}


Table 1.Disposition of study design

\begin{tabular}{lll}
\hline study variable & Studies(n) & Subjects(n) \\
\hline studies included & 18 & 1055 \\
$\begin{array}{l}\text { country } \\
\text { china }\end{array}$ & 6 & 371 \\
united states & 5 & 412 \\
south korea & 2 & 84 \\
india & 1 & 20 \\
Denmark & 1 & 60 \\
Turkey & 1 & 41 \\
the Netherlands & 2 & 67 \\
Study design & & \\
RCT & 15 & 915 \\
Non-RCT(case-control design) & 3 & 140 \\
disease type & & 505 \\
chronic ischemic cardiomyopathy (ICM) & 7 & 550 \\
acute myocardial infarction (AMI) & 11 & \\
stem cell characteristics & & \\
Cell source & & 230 \\
Allogeneic & 4 & \\
Autologous & 14 &
\end{tabular}

\section{Table 2.Study characteristics for AMI clinical trials}

\begin{tabular}{|c|c|c|c|c|c|c|c|}
\hline \multirow[b]{2}{*}{ number(n) } & \multirow[b]{2}{*}{ age(years) } & \multirow{2}{*}{$\begin{array}{c}\text { Time interva } \\
\text { between PCI } \\
\text { to injection } \\
\text { (days) }\end{array}$} & \multirow{2}{*}{ MSC source } & \multicolumn{2}{|c|}{ MSC characteristics } & \multirow[b]{2}{*}{ Route } & \multirow[b]{2}{*}{ Follow-up } \\
\hline & & & & cell type & MSCs No. & & \\
\hline 13 & $59.2 \pm 5$ & N/A & autologous & adipose tissue-derived & $2 \sim 4 \times 10^{7}$ & IC & 6 months \\
\hline 53 & $57.6 \pm 11.6$ & N/A & allogeneic & bone marrow-derived & $0.5,1.6,5 \times 10^{6}$ & $\mathrm{IV}$ & 6 months \\
\hline 20 & $47.6 \pm 9.5$ & N/A & allogeneic & bone marrow-derived & $4 \times 10^{6}$ & IV & 24 months \\
\hline 69 & $57.5 \pm 6$ & $18.3 \pm 0.4$ & autologous & bone marrow-derived & $8 \sim 10 \times 10^{9}$ & IC & 6 months \\
\hline 54 & $60.2 \pm 10.7$ & $21 \sim 31$ & autologous & bone marrow-derived & $<1 \times 10^{7}$ & TESI & 12 months \\
\hline 55 & $57 \pm 10$ & $15 \pm 0.5$ & autologous & bone marrow-derived & $20 \times 10^{7}$ & IC & 6 months \\
\hline 116 & $57 \pm 1.5$ & 5 & allogeneic & Umbilica & $6 \times 10^{6}$ & IC & 18 months \\
\hline 26 & $56.5 \pm 8.7$ & $30 \pm 1.3$ & autologous & bone marrow-derived & $7.2 \pm 0.90 \times 10^{7}$ & IC & 12 months \\
\hline 43 & $58.9 \pm 11$ & $14.07 \pm 9.53$ & autologous & bone marrow-derived & $2 \sim 5 \times 10^{5}$ & IC & 12 months \\
\hline 58 & $54 \pm 9.2$ & $25.0 \pm 2.4$ & autologous & bone marrow-derived & $7.2 \pm 0.90 \times 10^{7}$ & IC & 6 months \\
\hline 43 & $56.8 \pm 2.8$ & N/A & autologous & bone marrow-derived & $3.1 \pm 0.5 \times 10^{6}$ & IC & 24 months \\
\hline
\end{tabular}


Table 3.Study characteristics for ICD clinical trials

\begin{tabular}{|c|c|c|c|c|c|c|}
\hline & \multirow{2}{*}{ number(n) } & \multirow{2}{*}{ age(years) } & \multicolumn{3}{|c|}{ MSC characteristics } & \multirow{2}{*}{ Follow-up } \\
\hline & & & MSC source cell type & MSCsNo. & Route & \\
\hline Henry2016 & 31 & $64.8+7.7$ & autologous adipose tissue-derived & $4 \pm 0.9 \times 10^{7}$ & TESI & 6months \\
\hline perin 2014 & 27 & $63.6 \pm 7.5$ & autologous adipose tissue-derived & $4.2 \times 10^{7}$ & TESI & 18months \\
\hline CHART-12017 & 271 & $61.9 \pm 8.7$ & autologous bone marrow & $60 \times 10^{7}$ & TESI & 12months \\
\hline HUC.HEART & 41 & $63.2 \pm 9$ & allogeneic Umbilical & $2.1 \sim 2.6 \times 10^{7}$ & $\mathrm{Dl}$ & 12months \\
\hline TAC·HFT 2014 & 30 & $58.2 \pm 11$ & autologous bone marrow & $\mathrm{N} / \mathrm{A}$ & TESI & 12months \\
\hline MSC.HF trial 2015 & 60 & $65.5 \pm 8.7$ & autologous bone marrow & $7.8 \pm 6.8 \times 10^{7}$ & TESI & 6months \\
\hline Chen 2006 & 45 & $58.5 \pm 7.0$ & autologous bone marrow & $0.5 \times 10^{7}$ & IC & 3months \\
\hline
\end{tabular}

Figures

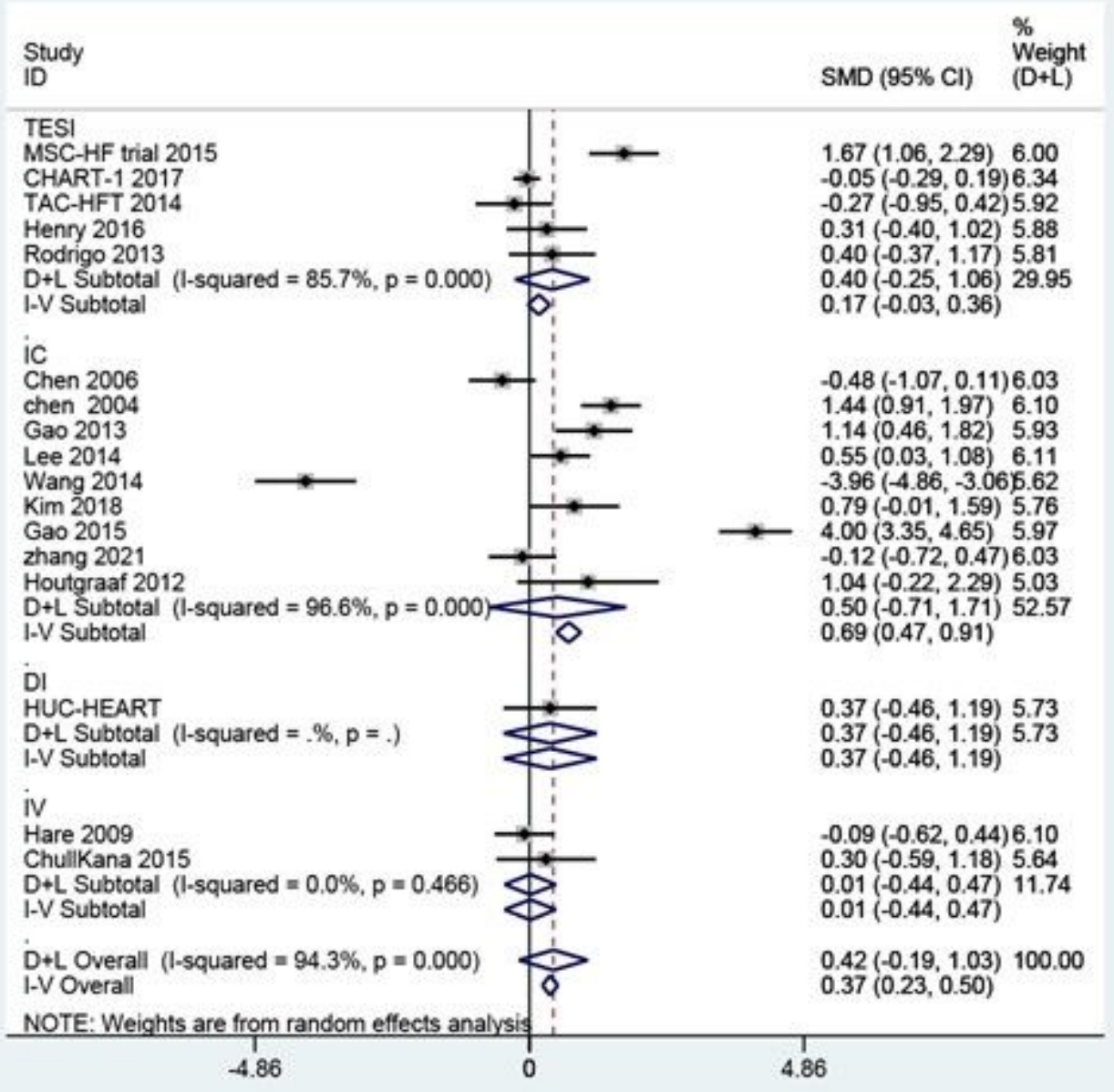

Figure 1 

compared with control. IC intracoronary, TESI transendocardial stem cell injection, IV intravenous, DI directly intramyocardia, $\mathrm{Cl}$ confidence interval

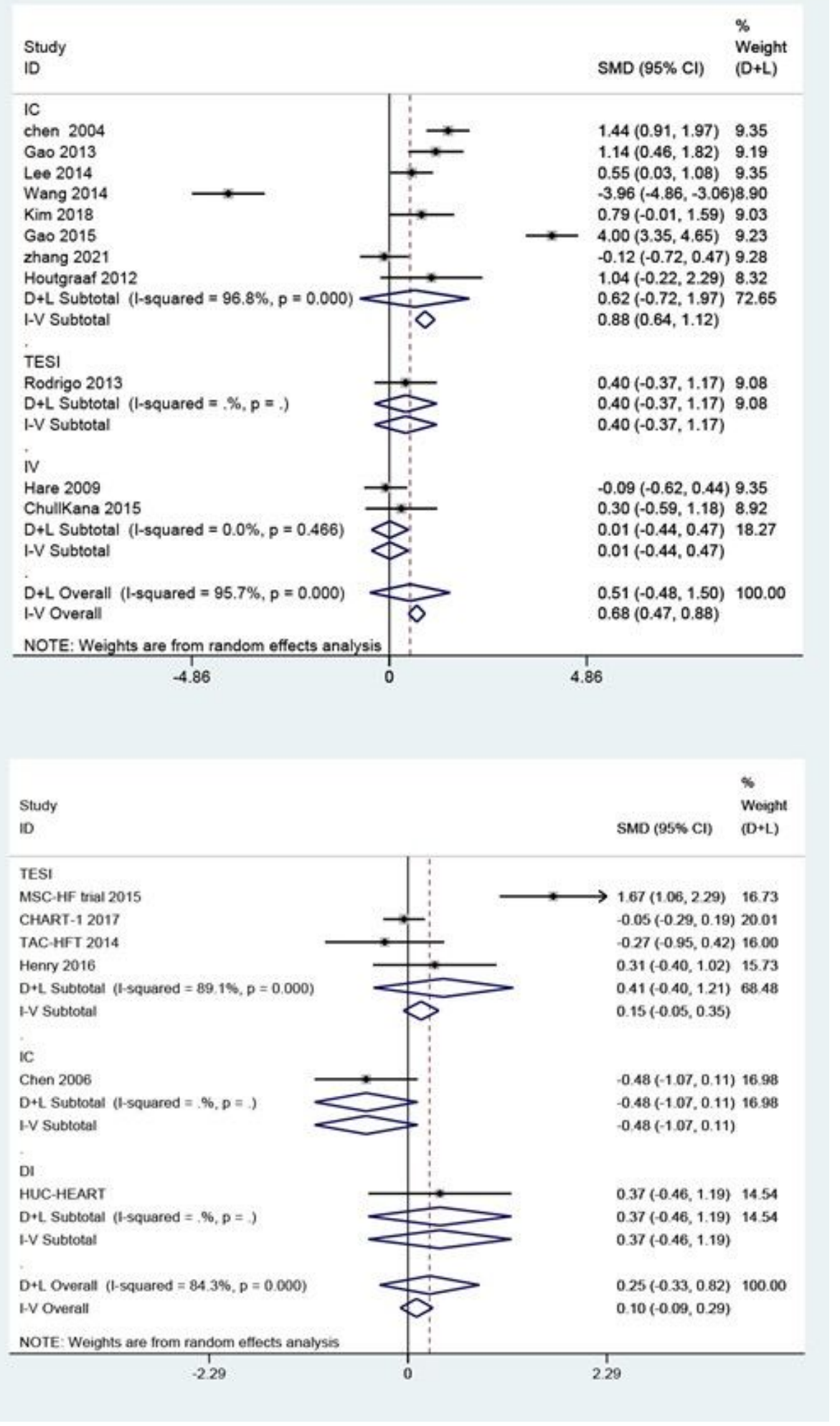

Figure 2

Impact of route of delivery MSC on LVEF within AMI or ICD patients. The figure above was in the AMI group, the below was in the ICD group. 


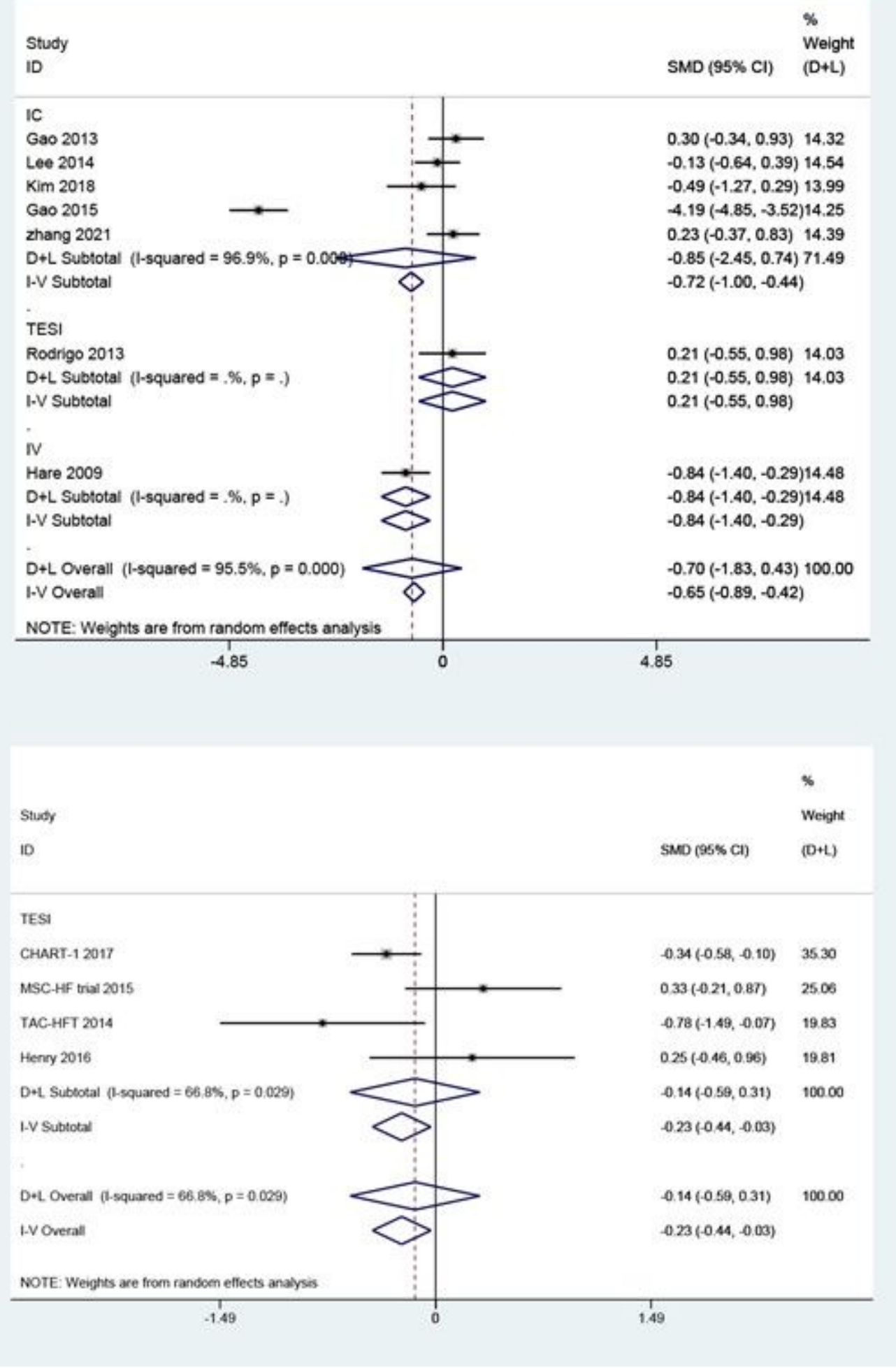

\section{Figure 3}

Impact of route of delivery MSC on LVEDV within AMI or ICD patients. The figure above was in the AMI group, the below was in the ICD group. 

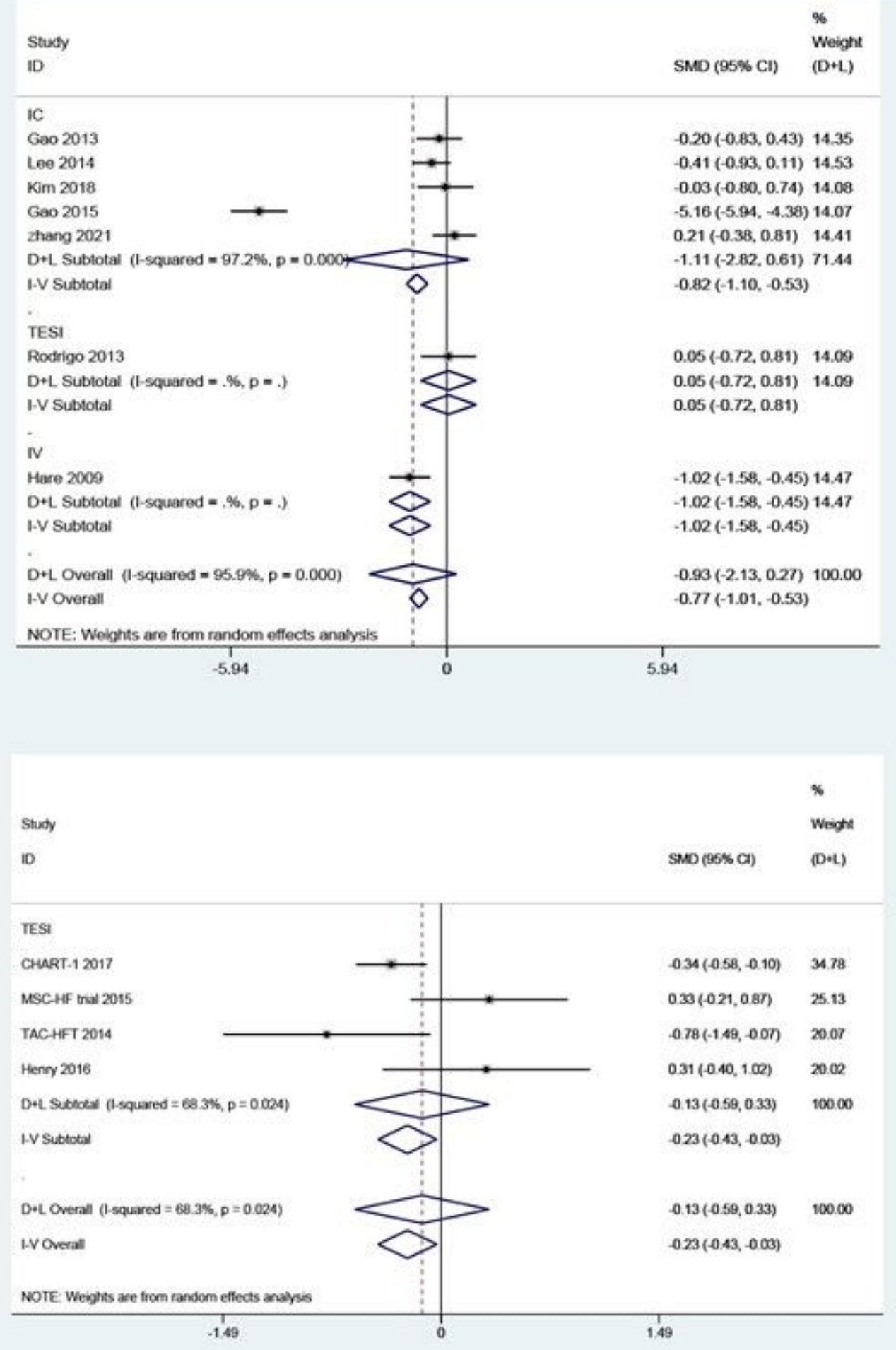

\section{Figure 4}

Impact of route of delivery MSC on LVESV within AMI or ICD patients. The figure above was in the AMI group, the below was in the ICD group. 
AMI

Zhang 2021

Kim 2018

Gao 2015

Lee 2014

Wang 2014

Gao 2013

Rodrigo 2013

Chullikana 2015

Hare 2009

D+L Subtotal

M-H Subtotal

ICM

HUC-HEART 2020

TAC-HFT 2014

henry 2016

Perin 2014

MSC-HF 2015

D+L Subtotal (I

M-H Subtotal

D $+L$ Overall ( 1 -squared $=0.0 \%, p=0.996$ ) M-H Overall

NOTE: Weights are from random effects analysis

01

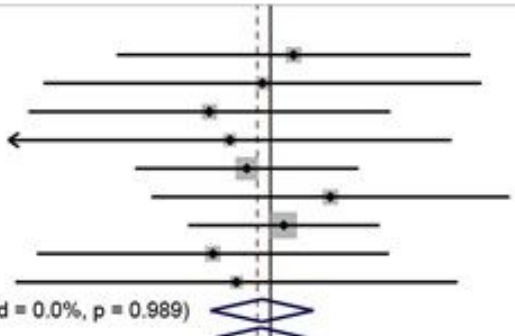

$1.50(0.07,33.61) 4.48$

$0.87(0.02,40.68) 2.92$

$0.34(0.01,8.22) 4.28$

$0.49(0.01,24.15) 2.85$

$0.66(0.09,4.70) \quad 11.23$

$2.87(0.12,66.75) 4.37$

$1.26(0.23,6.81) \quad 15.27$

$0.36(0.02,8.03) \quad 4.52$

$0.55(0.01,26.77) 2.87$

$0.86(0.35,2.13) 52.78$

$0.84(0.35,2.01)$

$1.00(0.12,8.56) 9.39$

$0.60(0.01,28.31) 2.91$

$3.75(0.19,72.49) 4.93$

$0.50(0.12,2.11) 21.07$

$0.52(0.06,4.74) 8.91$

$0.73(0.28,1.89) 47.22$

$0.83(0.33,2.07)$

$0.79(0.41,1.53) \quad 100.00$ $0.84(0.45,1.57)$

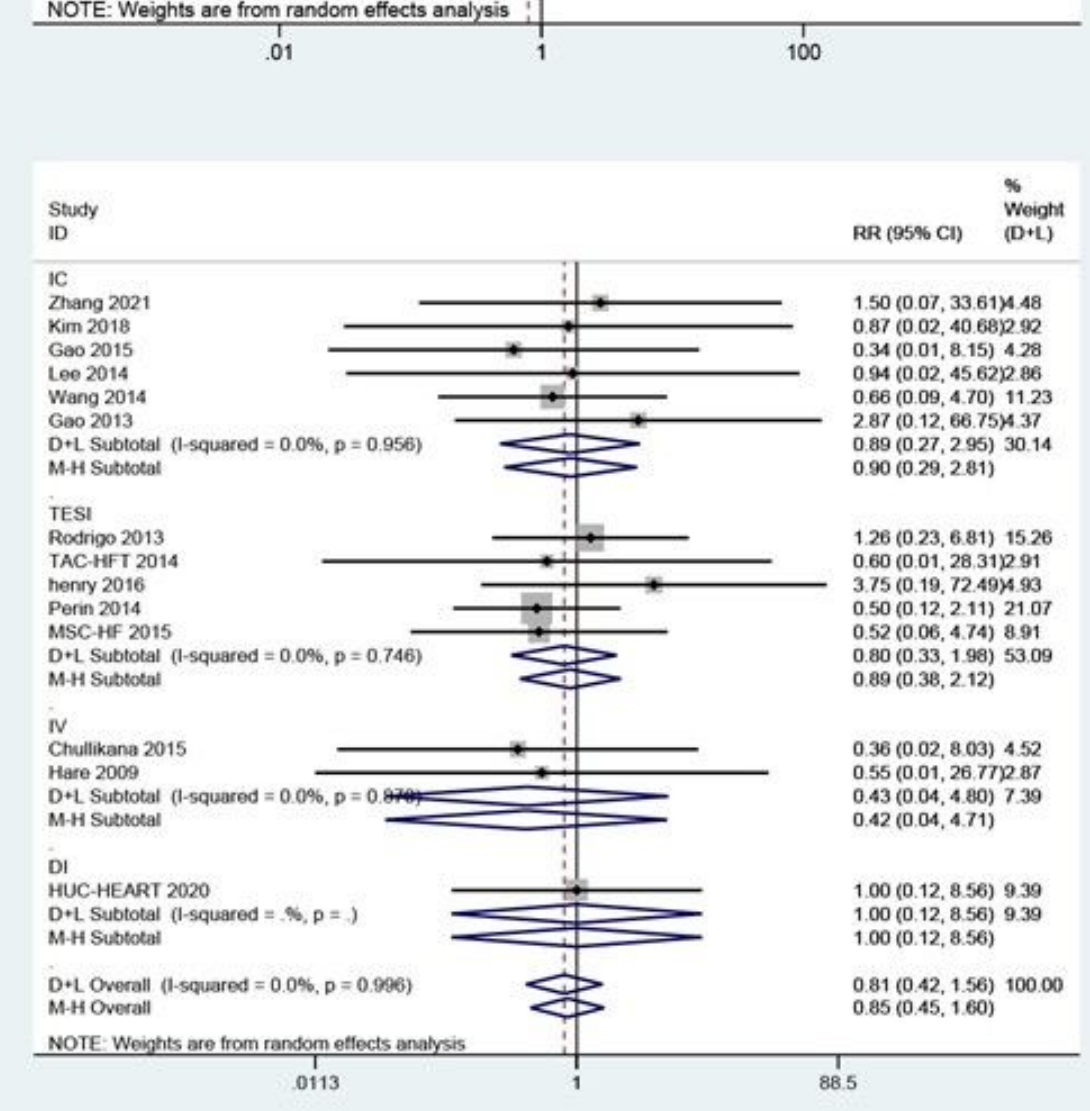

\section{Figure 5}

Impact of route of delivery MSC on mortality. The figure above explored the difference about mortality between AMI and ICD group, the below explored the difference about mortality when administered different route. 
Stuxty

ID
$\%$

Woight

$(\mathrm{D}+\mathrm{L})$

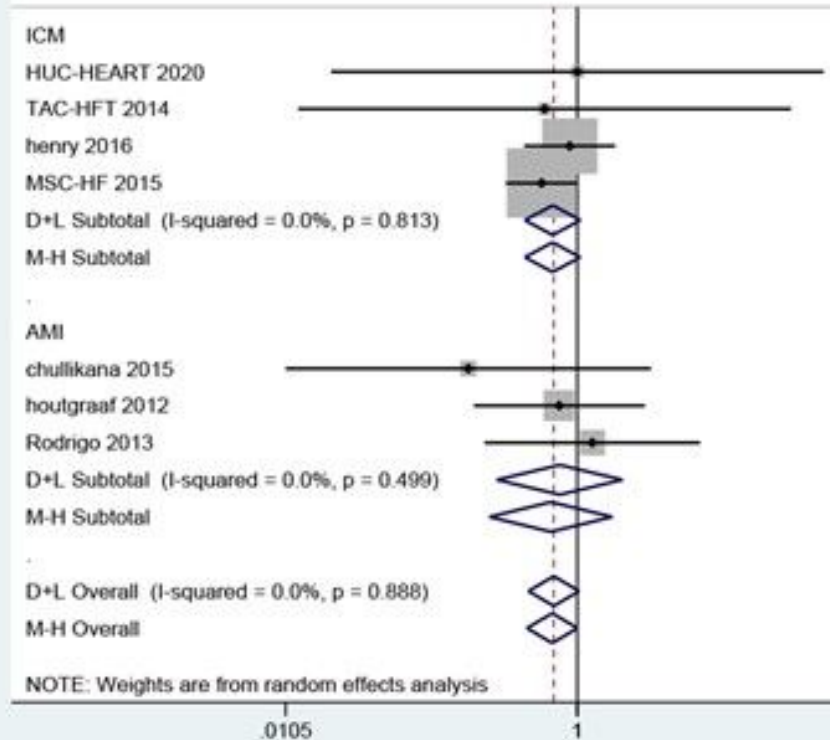

0105
RR $(95 \%$ Cl

$1.00(0.02,46.96) \quad 1.07$

$0.60(0.01,28.31) \quad 1.06$

$0.89(0.44,1.81) \quad 31.18$

$0.57(0.33,1.00) \quad 50.36$

$0.68(0.44,1.05) \quad 83.67$

$0.68(0.44,1.05)$

$0.18(0.01,3.16) \quad 1.94$

$0.75(0.20,2.87) \quad 8.82$

$1.26(0.23,6.81) \quad 5.57$

$0.76(0.28,2.03) \quad 16.33$

$0.66(0.25,1.73)$

$0.69(0.47,1.03) \quad 100.00$

$0.68(0.45,1.00)$

95.7

Study

10

D

HUC-HEART 2020

$D+L$ Subtotal (I-squared $=, \%, \rho=$ )

M-H Subtotal

TESI

TAC.HFT 2014

henry 2016

MSC-HF 2015

Rodrigo 2013

$D+L$ Subtotal ( $L$-squared $=0.0 \%, p=0.703$ )

M.H Subtotal

iv

chullikana 2015

$D+L$ Subtotal (1-squared $=\%, p=$.)

M-H Subtotal

ic

houtgraat 2012

$D *$ L Subtotal ( - squared $=\%, p=$ )

M-H Subtotal

$D+L$ Overall $(1-$ squared $=0.0 \%, p=0.889$ )

M-H Overall

NOTE: Weights are from random ellects analysis

0105
$\%$ $R R(95 \%$ Cl) $\quad(D+L)$

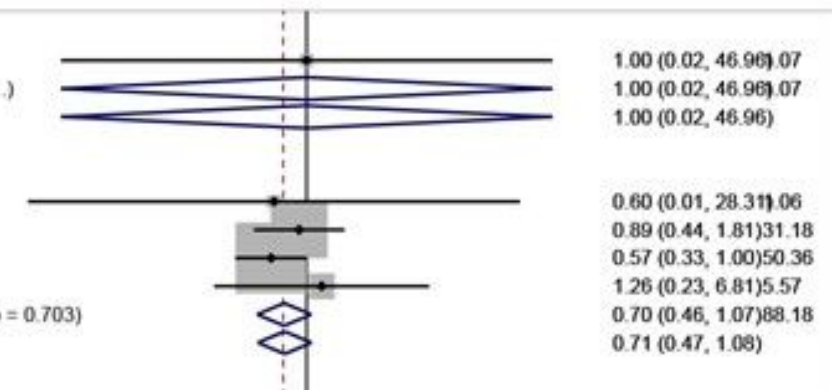

$0.18(0.01,3.16) 1.94$ $0.18(0.01,3.16) 1.94$ $0.18(0.01,3.16)$

$0.75(0.20,2.87) 8.82$ $0.75(0.20,2.87) 8.82$ $0.75(0.20,2.87)$

$0.69(0.47,1.03) 100.00$ $0.68(0.45,1.00)$

\section{Figure 6}

Impact of route of delivery MSC on Sever adverse event within AMI or ICD patients. The figure above explored the difference about Sever adverse event between AMI and ICD group, the below explored the difference about Sever adverse event when administered different route. 


Study
ID

\section{Figure 7}

Impact of route of delivery MSC on readmission.

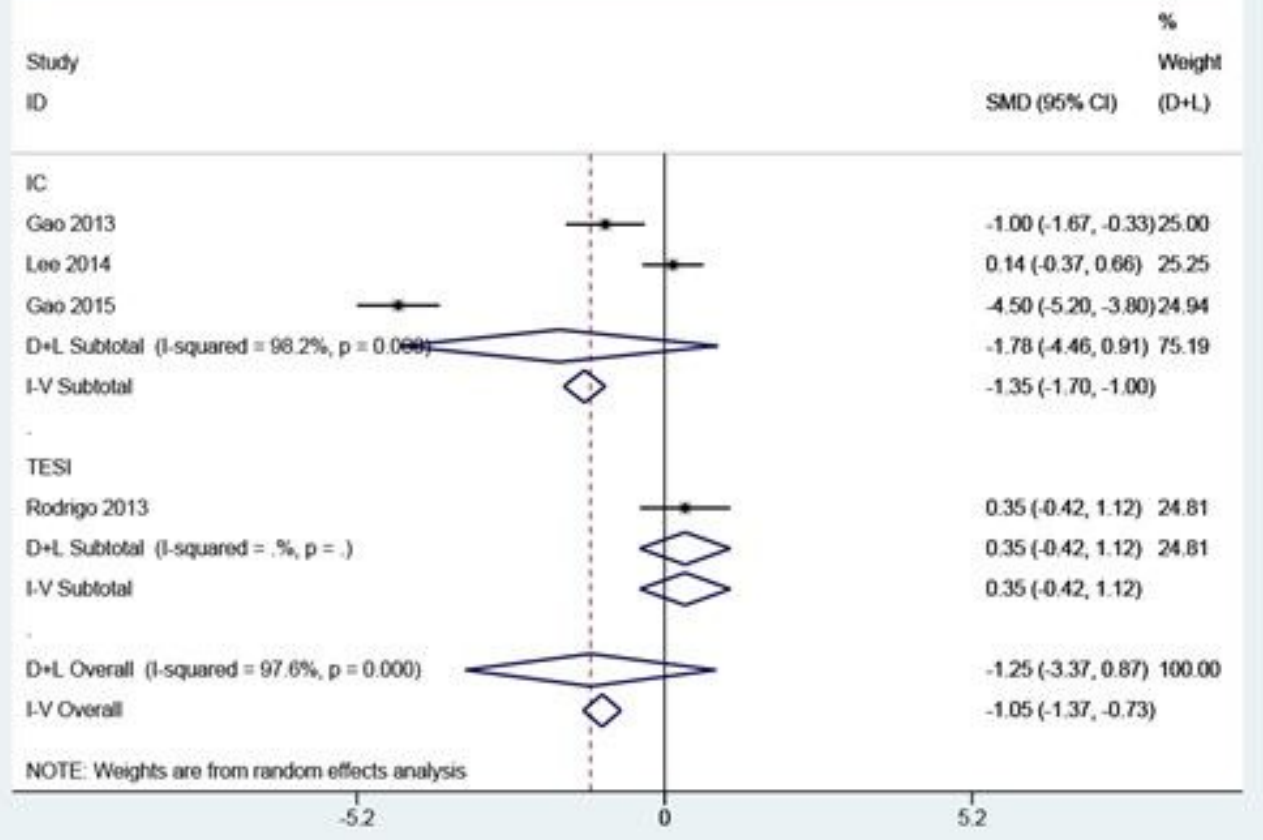

\section{Figure 8}


Impact of route of delivery MSC on WMSI.

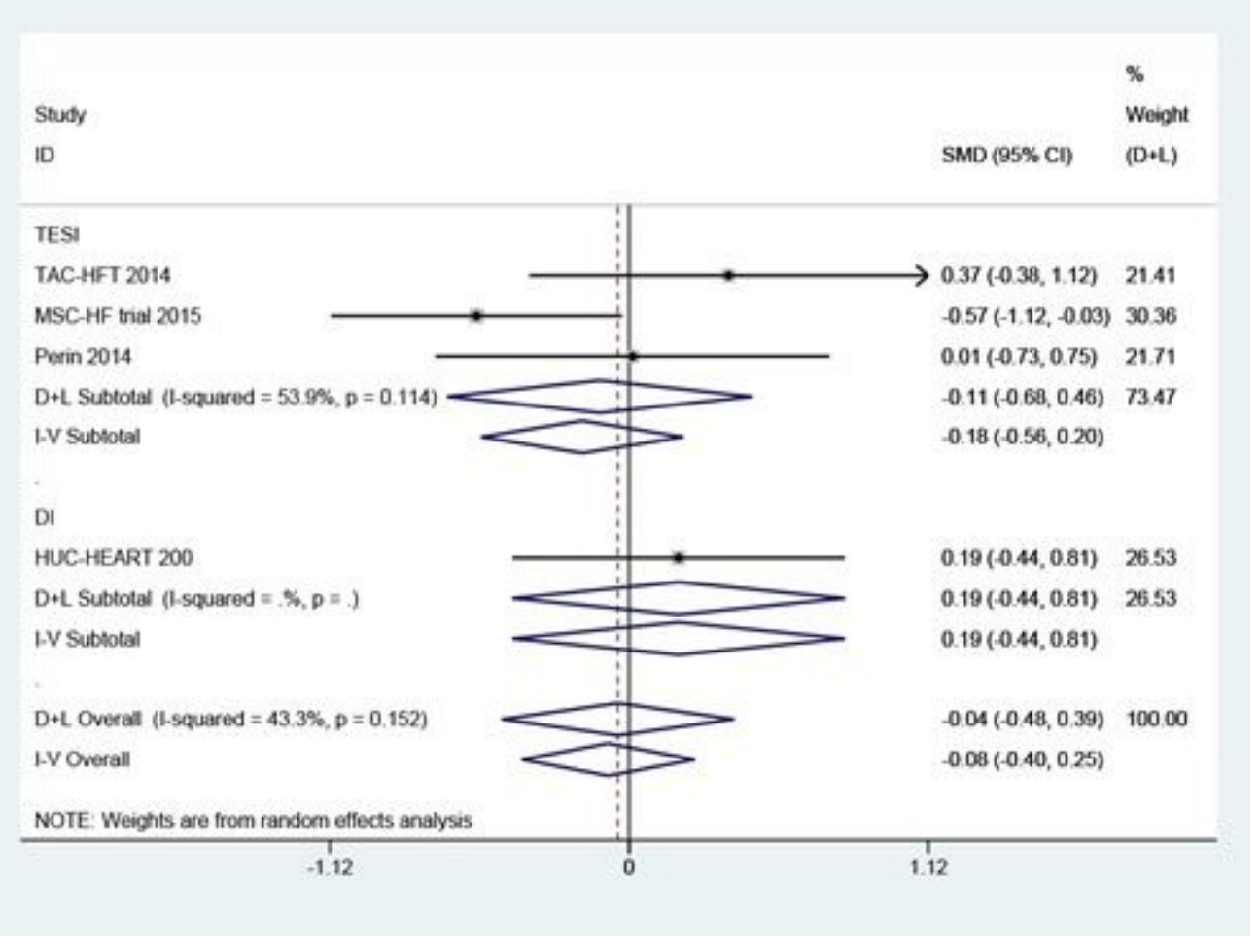

\section{Figure 9}

Impact of route of delivery MSC on 6min-walk. 


\begin{tabular}{|c|c|c|c|c|c|c|c|}
\hline & 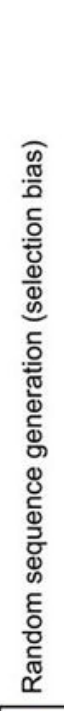 & 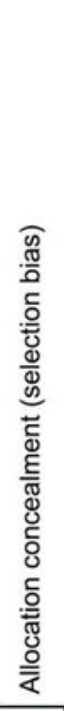 & 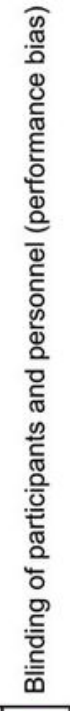 & 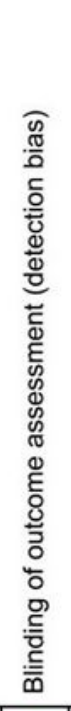 & 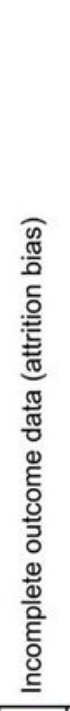 & 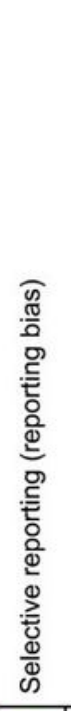 & 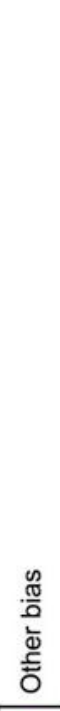 \\
\hline CHART-1 2017 & $?$ & ? & $\odot$ & $\odot$ & $\odot$ & + & + \\
\hline chen 2004 & $?$ & $?$ & $?$ & $?$ & $\odot$ & $?$ & + \\
\hline Chen 2006 & $?$ & $?$ & $?$ & $?$ & $\odot$ & $?$ & 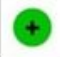 \\
\hline Chullikana 2015 & $\odot$ & $?$ & $?$ & $\odot$ & 0 & 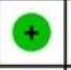 & + \\
\hline Gao 2013 & + & $?$ & 0 & $\odot$ & $\odot$ & $?$ & + \\
\hline Gao 2015 & $\odot$ & $?$ & $?$ & $\odot$ & $\odot$ & $\odot$ & + \\
\hline Hare 2009 & $\odot$ & + & + & $\odot$ & $\odot$ & + & + \\
\hline henry 2016 & $?$ & + & $\odot$ & $\odot$ & $\odot$ & $\odot$ & + \\
\hline houtgraaf 2012 & $?$ & ? & $?$ & $?$ & $\odot$ & + & + \\
\hline HUC-HEART 2020 & + & $?$ & $\odot$ & 0 & $\odot$ & 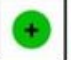 & $\odot$ \\
\hline Kim 2018 & $?$ & $?$ & 0 & 0 & $\odot$ & $?$ & + \\
\hline Lee 2014 & $?$ & 0 & 0 & $?$ & $\odot$ & + & + \\
\hline MSC-HF trial 2015 & + & $\odot$ & + & + & $\odot$ & + & + \\
\hline perin 2014 & $?$ & + & $\odot$ & $\odot$ & $\odot$ & $\odot$ & + \\
\hline Rodrigo 2013 & O & O & O & O & $\odot$ & $\odot$ & + \\
\hline TAC-HFT 2014 & O & $?$ & $\odot$ & + & $\odot$ & $\odot$ & $\odot$ \\
\hline Wang 2014 & $?$ & $?$ & $?$ & $\odot$ & $\odot$ & $?$ & + \\
\hline Zhang 2021 & + & 0 & 0 & 0 & $\odot$ & $\odot$ & + \\
\hline
\end{tabular}

Figure 10

Risk of Bias Assessment

\section{Supplementary Files}

This is a list of supplementary files associated with this preprint. Click to download. 
- Appendix1.xIsx

- Appendix2.xIsx

Page 24/24 